\title{
Simplified Method to Produce Human Bioactive Leukemia Inhibitory Factor in Escherichia coli
}

\author{
Houman Kahroba, ${ }_{1}^{1}$ Hamid Galehdari, ${ }^{1,}$ Mohammad Shafeei, ${ }^{1}$ Ali Khodadadi, ${ }^{2}$ Saeed Reza Khatami, ${ }^{1}$ \\ and Fatemeh Jalali ${ }^{1}$ \\ ${ }^{1}$ Department of Genetics, Shahid Chamran University, Ahvaz, IR Iran \\ ${ }^{2}$ Cancer, Petroleum and Environmental Pollutants Research Center, Jundishapur University of Medical Sciences, Ahvaz, IR Iran \\ "Corresponding author: Hamid Galehdari, Department of Genetics, Shahid Chamran University, Ahvaz, IR Iran. E-mail: galehdari187@yahoo.com
}

Received 2015 January 22; Accepted 2015 May 18.

\begin{abstract}
Background: Human leukemia inhibitory factor (hLIF) is a poly functional cytokine with numerous regulatory effects on different cells. Main application of hLIF is maintaining pluripotency of embryonic stem cells. hLIF indicated effective work in implantation rate of fertilized eggs and multiple sclerosis (MS) treatment. Low production of hLIF in eukaryotic cells and prokaryotic host's problems for human protein production convinced us to develop a simple way to reach high amount of this widely used clinical and research factor.

Objectives: In this study we want to purify recombinant human leukemia inhibitory factor in single simple method.

Materials and Methods: This is an experimental study, gene expression: human LIF gene was codon optimized for expression in Escherichia coli and attached his-tag tail to make it extractable. After construction and transformation of vector to E. coli, isopropyl $\beta$-D-1-thiogalactopyranoside (IPTG) used for induction. Single step immobilized metal affinity chromatography (IMAC) used for purification confirmed by Sodium dodecyl sulfate polyacrylamide gel electrophoresis (SDS PAGE) and western blotting. Bioactivity of the hLIF were tested by MTT assay with TF-1 cells and CISH gene stimulation in monocyte and TF-1 by real-time PCR. Induction by $0.4 \mathrm{mM}$ of IPTG in $25^{\circ} \mathrm{C}$ for 3 hours indicated best result for soluble expression. SPSS indicated P [U+02C2] 0.05 that is significant for our work.

Results: Cloning, expression, and extraction of bio active rhLIF was successfully achieved according MTT assay and real time PCR after treatment of TF-1 and monocyte cell lines.

Conclusions: We developed an effective single step purification method to produce bioactive recombinant hLIF in E. coli. For the first time we used CISH gene stimulating for bioactivity test for qualifying of recombinant hLIF for application.
\end{abstract}

Keywords: Recombinant Leukemia Inhibitory Factor, Codon Optimization, Bioactivity Assay, Escherichia coli

\section{Background}

Leukemia inhibitory factor (LIF) is a glycoprotein, classified as a sub-class of interleukin 6 cytokines with a wide biological function range and multiple effects on cells, human physiology and disease [1]. It was first characterized as an inducer of macrophage differentiation while it inhibits the growth of murine myeloid leukemia M1 cells. Also it regulates the survival of neurons, hematopoiesis, differentiation in embryonic stem cells, motility and survival rate of sperm, platelet numbers by effecting bone marrow function, improves survival of both sensory and motor neurons acute phase proteins embryo development [2-12]. HLIF is absolutely required for maintaining the stemness of embryonic stem cell (ESC) lines [13-16]. LIF-deficient mice demonstrate difficulties in blastocyst implantation [17], which suggests that administration of hLIF may aid the implantation rate of women displaying some forms of infertility [18]. The tyrosine kinase [Janus kinas (JAK)] binds constitutively to the intercellular domain of the LIF receptor complex in its inactive form. Upon LIF binding, JAK kinase activates transcription of signal transducers and activators of transcription (STAT) 1 and STAT 3 through SH2 domains. STAT proteins are then activated and translocated in to the nucleus, where they function as transcription factors $[19,20]$. CISH gene encodes a protein which contains a SH2 domain and a SOCS box domain. These proteins belong to cytokine-induced STAT inhibitor (CIS) that are suppressor of cytokine signaling (SOCS) or STAT-induced STAT inhibitor (SSI), protein family. CIS family members are known to be cytokine-inducible negative regulators of cytokine signaling. According to CISH Inducibility by LIF pathway, we choose it for treatment with homemade his 6-LIF to evaluate LIF bioactivity. Low expression of LIF in eukaryotic cells has been reported [3, 21]. Escherichia coli (E. coli) has higher expression, however the protein mis-folds and aggregates to form inclusion bodies (IBs) in prokary- 
otic hosts is common [22]. In general, the solubilization of IBs requires high concentrations of denaturants, such as urea or guanidine hydrochloride and subsequent refolding via the removal of the denaturants. In many cases the overall yield of biologically active protein from IBs is low [23].

\section{Objectives}

In present study, we tried to clone and codon optimizes the human LIF gene effectively and produces the recombinant protein easily by simple IPTG induction and is able to purify it by single step. We observed that low temperature significantly improves the solubility of hLIF as a fusion protein in E. coli. Also we established a single step protocol for purifying bioactive hLIF relying on His-tag tail by immobilized metal affinity chromatography. The bioactivity of fused hLIF was tested by MTT assay and CISH gene stimulation assay by real time PCR that confirmed its bioactivity.

\section{Materials and Methods}

This is an experimental study, materials and methods divides to:

\subsection{Gene Expression Assay}

\subsubsection{Construction of Expression Vector}

The hLIF gene includes 181 amino acid codons for polypeptide synthesis (NCBI reference sequence: MN002309.3) was synthesized for fully expression in $E$. coli (Gen Fanavaran Ldt, Tehran, Iran). The codons were optimized for E. coli in order to improve the expression of hLIF. Each amino acid includes several codes in DNA sequence; the most frequent codes were choosed instead of human common codes. Then optimized sequence inserted into the expression vector pET-28a (+) with BamHI and XbaI restriction sites (Generay Biotech Co, Ltd). pET-28a (+) introduces kanamycin resistance in drug sensitive host with the T7lac promoter for stable transcription. Also adds $6 x$ His-tag sequence in the N-terminal of heterogen protein to facilitate the purification step of the protein and also adds a thrombin site for removing the His-Tag sequence from recombinant hLIF after purification [24].

\subsubsection{Expression and Purification of rLIF}

The modified pET28a (+) vector vectors were transformed into competent E. coli BL21 (DE3) host cells treated by $\mathrm{Mgcl}_{2}$ and transformation approved by bacteria culture in kanamycin added medium and plasmid extraction. The transformants were cultured at $37^{\circ} \mathrm{C}$ in LB medium containing $30 \mu \mathrm{g} / \mathrm{mL}$ kanamycin or $50 \mu \mathrm{g} / \mathrm{mL}$ ampicillin (as appropriate), and the target protein expression was induced using $0.5 \mathrm{mM}$ isopropyl- $\beta$-D-thiogalactoside (IPTG) when the optical density at $600 \mathrm{~nm}$ (OD600) reached 0.7 - 0.8 au (approximately 3 hours). After the addition of $0.4 \mathrm{mM}$ IPTG, the culture was maintained at $37^{\circ} \mathrm{C}$ for alternative $3-7$ hours in order to increase protein solubility. All expression levels were analyzed using sodium dodecyl sulfate-polyacrylamide gel electrophoresis (SDS-PAGE) with $12 \%$ Tris-glycine gel.

\subsubsection{Purification of rhLIF}

Cells were harvested by centrifugation at $4000 \mathrm{x} \mathrm{g}$ for 15 minutes at $4^{\circ} \mathrm{C}$, and the cell pellets were resuspended in 5 - $10 \mathrm{~mL}$ binding buffer ( $20 \mathrm{mM}$ sodium phosphate, 500 $\mathrm{mM} \mathrm{NaCl}, 20 \mathrm{mM}$ imidazole, $\mathrm{pH}=7.4$ ) for remove nonspecifically bound proteins, applied $3 \mathrm{~mL}$ elution buffer (20 mM sodium phosphate each gram of cell paste. Enzymatic digestion ( $0.2 \mathrm{mg} / \mathrm{mL}$ lysozyme, $1 \mathrm{mM} \mathrm{MgCl}_{2}, 1 \mathrm{mM}$ PMSF) starts for 30 minutes at room temperature. Then lysate was sonicated 6 - 10 times on ice for 30 seconds with 1 min interruptions. Then the supernatant was clarified by centrifugation at $20,000 \mathrm{x}$ for 10 minutes at $4^{\circ} \mathrm{C}$ and filtered through a $0.45 \mu \mathrm{m}$ syringe filter (biochrom, England). The overexpressed hLIF fusion protein was initially purified using immobilized metal ion affinity chromatography (IMAC). At first column was equilibrated with $10 \mathrm{~mL}$ of binding buffer then the collected supernatant in previous step were added and ran. Then column washed with 10 mL binding buffer to, $500 \mathrm{mM} \mathrm{NaCl}, 500 \mathrm{mM}$ imidazole, $\mathrm{pH}$ $=7.4$ ) and collected the eluate and purified His6-hLIF and sterilized the production $(0.2 \mu$ filter $)$ and stored at $-20^{\circ} \mathrm{C}$ until further study.

\subsubsection{Electrophoresis, Silver Staining and Western Blot Analysis}

All purified proteins were analyzed using SDS-PAGE [25]. Protein samples were denatured in $5 \mathrm{x}$ sample buffer [0.2 M Tris-HCl, $\mathrm{pH}=6.8,20 \%$ glycerol (v/v), 10\% SDS $(\mathrm{w} / \mathrm{v}), 0.05 \%$ bromophenol blue $(\mathrm{w} / \mathrm{v})]$ containing $10 \% \beta$ mercaptoethanol (v/v) for 5 minutes at $95^{\circ} \mathrm{C}$. Samples were loaded into $12 \%$ polyacrylamide gels. Fractionated proteins were developed using Coomassie Brilliant Blue R-250 stain and silver stain (Merck). The silver staining was stopped using $5 \%$ acetic acid ( $\mathrm{v} / \mathrm{v})$ for 15 minutes once the bands were clearly visible. Gels were washed with water, incubated overnight and preserved in an aqueous solution containing $5 \%$ glycerol (v/v) and $0.02 \%$ sodium azide (w/v). After assuring of protein band existing by Ponceau $S$ staining of SDS-PAGE gels, protein fractions transferred to polyvinylidene fluoride (PVDF) membrane (Millipore) by electro elution at $60 \mathrm{~V}$ for 3 hours. The PVDF membrane was incubated overnight in blocking buffer [ $5 \% \mathrm{w} / \mathrm{v}$ skim milk (Merck) in 
0.05\% v/v Phosphate-buffered saline (PBS)-Tween-20 solution] at $4{ }^{\circ} \mathrm{C}$, followed by washing 3 times with PBS-Tween20 and shaking in $50 \mathrm{rpm}$ for an hour in 1: 200 dilution of mouse monoclonal LIF antibody (Santa Cruz biotechnology, Inc.), with repeating washing step 3 times with PBSTween 20. The membrane was then incubated with 1/2000 dilution of a goat anti-mouse IgG peroxidase conjugate (Sigma) and the signal was detected by 4-chloro-1-naphthol (Biogen, Iran) substrate solution.

\subsubsection{Biological Activity \\ 3.1.5.1. MTT Cell Proliferation Assay}

Bioactivity of His6-LIF was measured by ability to promote proliferation of human erythroleukemia cells (TF1). TF-1 cells were grown in Dulbecco's Modified Eagle's Medium (DMEM) medium (GIBCO @) containing 10\% fetal calf serum. The TF-1 cell line is unique because of its responsiveness to multiple lymphokines and cytokines of such as interleukin 1 (IL-1), interleukin 4 (IL-4), interleukin 6 (IL-6), interleukin 9 (IL-9), interleukin 11 (IL-11), interleukin 13 (IL13), stem cell factor (SCF), leukemia inhibitory factor (LIF) and nerve growth factor (NGF). Before the assay, TF-1 cells were cultured without GM-CSF for 24 hours prior to treatment with His6-LIF ( 0.05 - $50 \mathrm{ng} / \mathrm{mL})$ and seeded into a 96well plate at a density of $5 \times 10^{3}$ cells/well. After 72 hours incubation at $37^{\circ} \mathrm{C}, 5 \% \mathrm{CO}_{2}$ in air, 3-(4, 5-dimethylthiazol-2yl)-2, 5diphenyltetrazolium bromide(MTT, Invitrogen) was added and incubated for an additional 4 hours. After the formation of formazan crystals, $10 \%$ SDS in $10 \mathrm{mM} \mathrm{HCl}$ was added and incubated at $37^{\circ} \mathrm{C}, 5 \% \mathrm{CO}_{2}$ in air overnight, to dissolve the crystals. After overnight incubation, the absorbance was measured at $570 \mathrm{~nm}$.

\subsubsection{Quantitative Real-Time PCR}

Two types of cell lines were used for this propose, monocytes and TF-1 cells. Monocytes were extracted by Ficoll from whole blood. Heparinized blood smoothly added on Ficoll in 1:1 ratio, then centrifuged in $200 \mathrm{~g}$ for 10 minutes and supernatant were discarded and sediment cells were gently mixed with rich medium and transferred into the culture flasks, incubated in $37^{\circ} \mathrm{C}$, 95\% humidity and $5 \% \mathrm{Co}_{2}$ for 1 hour then medium was discarded (monocytes attached to flask surface) and fresh rich medium were added. For treatment of each cell lines with homemade rLIF two groups were chosen, treated and untreated cells. Cells harvested 48 and 72 hours. $\mathrm{CISH}$ induction has main effect on cell and causes fate determination such as growth, proliferation, development and immunity. Total RNA was extracted using the RNeasy Mini Kit (Qiagen, Germany). RNA was extracted from cells and cDNA was obtained from total RNA using BIONEER kit [AccuPower CycleScript RT PreMix (Dn6)].
The resulting cDNA was used to perform quantitative real-time polymerase chain reaction (qRT-PCR) using fast start SYBR green master (Roche Applied Science, Germany) in an $\mathbf{S 1 0 0 0}$ thermal cycler (Bio-Rad Laboratories). $\beta$-actin was used as the endogenous control to normalize the expression levels. cDNA was amplified using the following primer sets: CISH- F 5'-GTAGAGGGGAAGCTGAGGCT3', R 5'-CGAGGTCTAGAAGGCAGTGG-3' (Accession NO: NG-023194.1) and glyceraldehyde-3-phosphate dehydrogenase (GAPDH) F: 5'-GCTCTTTTCCAGCCTTCCTT-3', R: 5'-CTTCTGCATCCTGTCAGCAA-3' used as reference gene. The thermo cycling protocol included pre-incubation at $95^{\circ} \mathrm{C}$ for 2 minutes and 30 cycles at $95^{\circ} \mathrm{C}$ for $30 \mathrm{~s}, 62^{\circ} \mathrm{C}$ for $30 \mathrm{~s}, 72^{\circ} \mathrm{C}$ for $45 \mathrm{~s}$ and finally at $72^{\circ} \mathrm{C}$ for 2 minutes (www.genescript.com). For statical analysis we used SPSS. $P$ value indicated less that 0.05 that means our work is significant.

\section{Results}

\subsection{Expression and Purification of Recombinant Optimized LIF Fusion Protein}

For the highest output of soluble recombinant fusion protein, different concentrations of IPTG (0.2, 0.5, 1.0 mM), and induction temperatures $\left(25,30\right.$ and $\left.37^{\circ} \mathrm{C}\right)$ were used to optimize. For this propose, transformed E. coli were cultured at $37^{\circ} \mathrm{C}$ and when the culture OD600 reached 0.7 0.8 , the temperature was decreased to 25,30 or $37^{\circ} \mathrm{C}$ and IPTG was added and incubated for 3 - 7 hours. The longer the incubation time caused the more formation of inclusion body (IBs) and the less soluble recombinant protein. Chromatography column used to purification of recombinant protein that binds to his 6-tag of expressed hLIF. The amount and purity of rLIF from different inducer concentration and induction time were analyzed by SDS-PAGE and spectrophotometer (Figure 1). Induction by $0.4 \mathrm{mM}$ of IPTG for 3 hours resulted in most soluble recombinant protein. In all inducer concentrations and all the induction times, recombinant protein was expressed and SDS-PAGE approved it. The purification of the recombinant LIF was done by single step immobilized metal affinity chromatography (IMAC) with elution containing $500 \mathrm{mM}$ imidazole. For washing nonspecific binding proteins the column was washed by binding buffer. The diagram of rLIF purification by chromatography is indicated in Figure 1.

SDS-PAGE gel staining results approved purification of rhLIF, gel staining was done by Coomasie Brilliant Blue R250 and silver staining (Figure 2). Western blotting proved accuracy of chromatography purification (Figure 3 ). 
A : Induction with $0.2 \mathrm{mM}$ IPTG

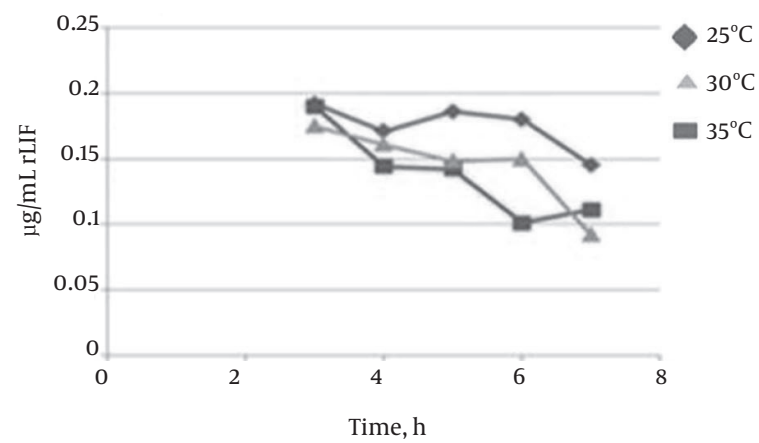

B : Induction with 0.4mM IPTG

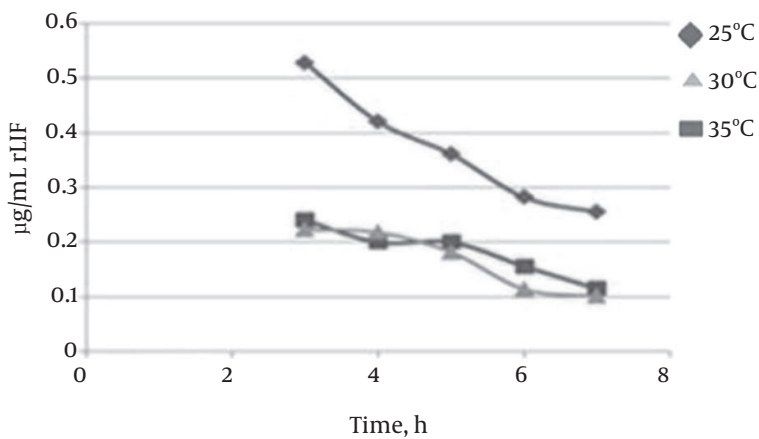

A and B indicate induction by two different IPTG concentrations. Induction by $0.4 \mathrm{mM}$ of IPTG for 3 hours in $25^{\circ} \mathrm{C}$ has the most output of purification.

Figure 2. SDS PAGE Analyzes
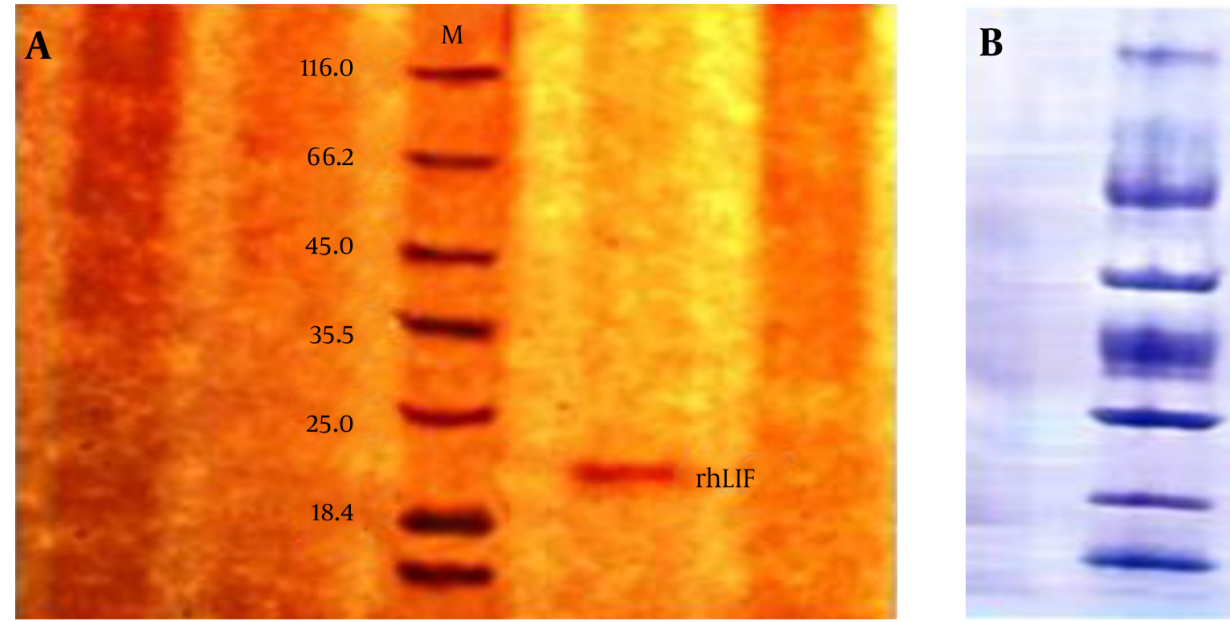

A, SDS PAGE silver nitrate staining; B, Coomasie brilliant blue R-250.

\subsection{Bioactivity of LIF}

\subsubsection{MTT Assay}

To assess the biological activities of the rLIF expressed in E. coli, their ability in induction of TF-1 cell proliferation with MTT assay used. LIF biactivity can be characterized on the basis of its ability to stimulate the proliferation of human erythroleukemia (TF-1) cells. The results indicated that His 6-proteins obviously promote the proliferation of TF-1 cells (Figure 4). This study indicated that the His 6-hLIF protein was an effective factor in inducing TF-1 cells proliferation, so added His-tag at the N-terminal of the rLIF protein do not interfere with bioactivity (Figure 4).

\subsubsection{Real Time PCR}

In addition, purified His 6-hLIF fusion protein was tested for its ability to induce cytokine inducible $\mathrm{SH} 2-$ containing protein (CISH) which is a key gene in LIF receptor pathway which is inducable by IL2, IL3, IL6, and IL10(interleukin 2,3,6,10) family, Gamma interferon factor (INF), granulocyte-macrophage colony-stimulating factor) (GM-CSF) and epidermal calcium binding protein (EPO) that results in proliferation, growth, development and immunity. CISH (cytokine inducible $\mathrm{SH}$ 2-containing protein) induction were tested by real time PCR, two cell lines were used for this propose human monocytes that was extracted from whole blood and TF-1. LIF effects CISH expression in monocytes according to immune response and in TF-1, 


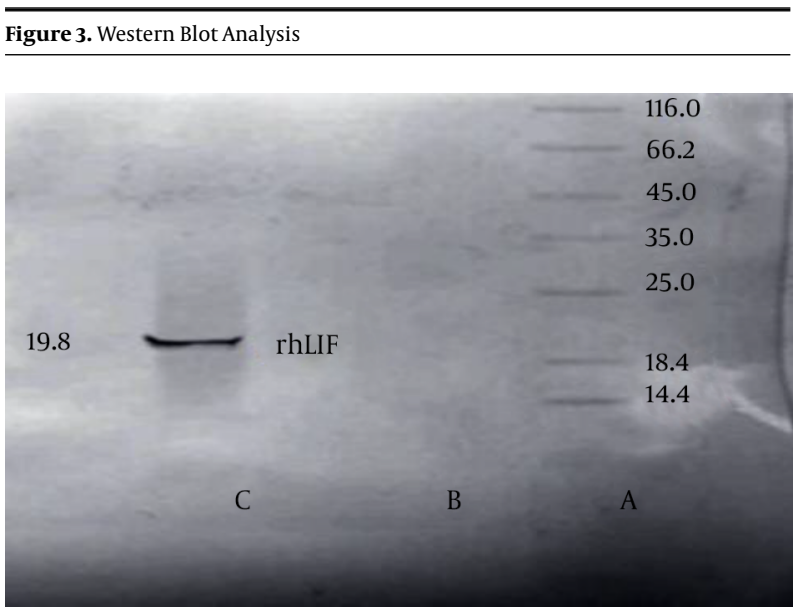

A, protein molecular weight Marker; B, Transformed E. coli expressing hLIF protein, C: negative control. Desired protein band indicated by arrow.

Figure 4. Bioactivity Assay of Recombinant hLIF on TF-1 Cells by MTT Assay Cell Absorption in $580 \mathrm{~nm}$ After 72 Hours (Read With Elisa Reader)

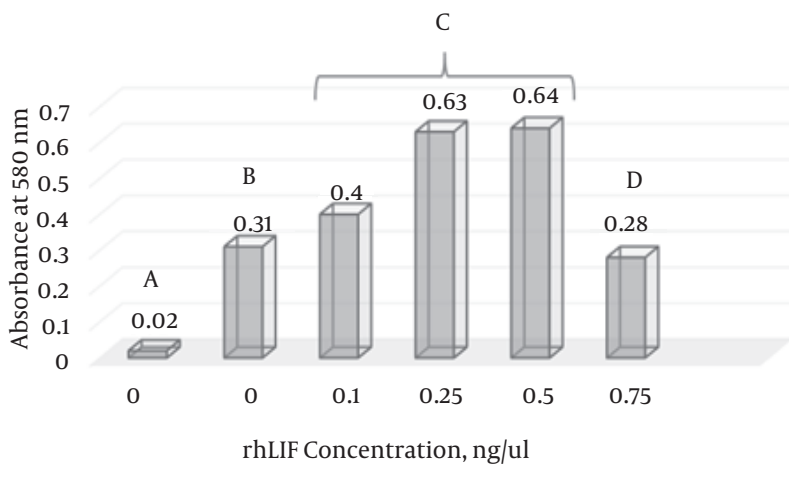

A, media without cell; B, untreated cells; $C$, treated cells with different concentration of rhLIF; D, Dead cells because of high rhLIF concentration.

CISH makes cells to proliferate. After real time PCR reactions, result analyzing indicated an over expression of the CISH after treatment with LIF in contrast to control samples. Over expression of CISH is a reason for rhLIF bioactivity.

\section{Discussion}

In present study, we approached cloning and optimized expression by codon optimization of the human LIF gene. We effectively produced the recombinant protein easily by simple $0.4 \mathrm{mM}$ of IPTG induction for 3 hours was able to purify it by single affinity chromatography step. We observed that low temperature significantly improves the solubility of hLIF as a fusion protein in E. coli. Also we established a single step protocol for purifying bioactive hLIF relying on His-tag tail by immobilized metal affinity chromatography. The bioactivity of fused hLIF was tested by MTT assay and CISH gene stimulation assay by real time PCR that confirmed its bioactivity.

Degeneracy of the genetic codes can interfere with protein producing in hosts manipulated with external genomic DNA from different species that is result of wobble codons are used differently in prokaryotic common hosts. To solve this we optimized LIF codons for bacteria to gain the recombinant protein easily [23]. The other effective factor in producing recombinant protein in bacteria is temperature that can handles forming of inclusion bodies made of recombinant protein because of over expression, to solve this we cultured and inducted cells in different temperatures as other studies but we tried to combine this tempreture alternation with inducer concentration $[24,25]$. To validate the functionality of hLIF, we applied MTT assay as previously reported [26]. The other specifies of our work is single step of purification just by simple affinity chromatography that do not need any subsequent modifying for activating rhLIFT we attached his-tag to the end of the recombinant protein to be able to extract rhLIF easily but in others studies they fuse insoluble agents like s-glutathione transferase to recombinant LIF to make it soluble in cytoplasm for easy extrction. In contrast to other similar works that further modifications is needed to break insoluble agent to obtain bioactive recombinant protein, like separating signal peptide we did not need such extra works [27]. In different studies adding signal peptide made soluble recombinant protein that inhibits inclusion body formation but we reduced this by temperature factor. For measuring LIF bioactivity for the first time we used a key gene that lies in LIF pathway. A method which is sensitive and rapid against embryonic stem cell cultivating and treatment by LIF that costs high. But other studies used stem cell culturing that is high cost and is not easily accessible. In other studies they use stem cell cultivation for indicating rhLIF activity to preserve polypotency but we used a key house-keeping gene that is responsible for LIF effect on different cells and tissues, we examined this gene by Real Time PCR against using highly cost stem cell cultivation [6].

\section{Acknowledgments}

The authors hereby express their gratitude and thank to the Shahid Chamran University for providing grant number 9010206. 


\section{Footnotes}

Authors' Contribution: Hamid Galehdari: project designer and Manager; Houman Kahroba: performing experiments;

Funding/Support: Mohammad Shafiee: management of biochemical assay; Ali Khodadadi: designed MTT assay and real-time PCR; Saeedreza Khatami: draft designer; Fateme Jalali: experimental co-worker.

\section{References}

1. Hilton DJ. LIF: lots of interesting functions. Trends Biochem Sci. 1992;17(2):72-6. [PubMed: 1566332].

2. Rassouli H, Nemati S, Rezaeiani S, Sayadmanesh A, Gharaati MR, Salekdeh GH, et al. Cloning, expression, and functional characterization of in-house prepared human leukemia inhibitory factor. Cell J. 2013;15(2):190-7. [PubMed: 23862122].

3. Gough NM, Gearing DP, King JA, Willson TA, Hilton DJ, Nicola NA, et al. Molecular cloning and expression of the human homologue of the murine gene encoding myeloid leukemia-inhibitory factor. Proc Natl Acad Sci U S A. 1988;85(8):2623-7. [PubMed: 3128791].

4. Cheema SS, Richards LJ, Murphy M, Bartlett PF. Leukaemia inhibitory factor rescues motoneurones from axotomy-induced cell death. Neuroreport. 1994;5(8):989-92. [PubMed: 8061310].

5. Cheema SS, Richards L, Murphy M, Bartlett PF. Leukemia inhibitory factor prevents the death of axotomised sensory neurons in the dorsal root ganglia of the neonatal rat.J Neurosci Res. 1994;37(2):213-8. doi: 10.1002/jnr.490370207. [PubMed: 8151729].

6. Imsoonthornruksa S, Noisa P, Parnpai R, Ketudat-Cairns M. A simple method for production and purification of soluble and biologically active recombinant human leukemia inhibitory factor (hLIF) fusion protein in Escherichia coli. J Biotechnol. 2011;151(4):295-302. doi: 10.1016/j.jbiotec.2010.12.020. [PubMed: 21219946].

7. Wobus AM, Boheler KR. Embryonic stem cells: prospects for developmental biology and cell therapy. Physiol Rev. 2005;85(2):635-78. doi: 10.1152/physrev.00054.2003. [PubMed: 15788707].

8. Fakher R, Saki G. Assessment of motility survival rate of asthenospermic men's sperm cultured in media pluse leukemia inhibitor factor. Int J Pharmacol. 2010;6(3):306-10.

9. Metcalf D, Nicola NA, Gearing DP. Effects of injected leukemia inhibitory factor on hematopoietic and other tissues in mice. Blood. 1990;76(1):50-6. [PubMed: 2114187].

10. Mikolajczyk M, Skrzypczak J, Szymanowski K, Wirstlein P. The assessment of LIF in uterine flushing-a possible new diagnostic tool in states of impaired fertility. Reprod Biol. 2003;3(3):259-70. [PubMed: 14688825].

11. Richter KS. The importance of growth factors for preimplantation embryo development and in-vitro culture. Curr Opin Obstet Gynecol. 2008;20(3):292-304. doi: 10.1097/GCO.0b013e3282fe743b. [PubMed: 18460945].

12. Dimitriadis E, Menkhorst E, Salamonsen LA, Paiva P. Review: LIF and IL11 in trophoblast-endometrial interactions during the establishment of pregnancy. Placenta. 2010;31 Suppl:S99-104. doi: 10.1016/j.placenta.2009.12.027. [PubMed: 20129664]
13. Hirai H, Karian P, Kikyo N. Regulation of embryonic stem cell selfrenewal and pluripotency by leukaemia inhibitory factor. Biochem J. 2011;438(1):11-23. doi: 10.1042/BJ20102152. [PubMed: 21793804].

14. Majumder A, Banerjee S, Harrill JA, Machacek DW, Mohamad O, Bacanamwo M, et al. Neurotrophic effects of leukemia inhibitory factor on neural cells derived from human embryonic stem cells. Stem Cells 2012;30(11):2387-99. doi: 10.1002/stem.1201. [PubMed: 22899336].

15. Smith AG, Nichols J, Robertson M, Rathjen PD. Differentiation inhibiting activity (DIA/LIF) and mouse development. Dev Biol. 1992;151(2):339-51. [PubMed: 1601171].

16. Alexandrova S, Kalkan T, Humphreys P, Riddell A, Scognamiglio R Trumpp A, et al. Selection and dynamics of embryonic stem cell integration into early mouse embryos. Development. 2016;143(1):24-34. doi: 10.1242/dev.124602. [PubMed: 26586221].

17. Chen JR, Cheng JG, Shatzer T, Sewell L, Hernandez L, Stewart CL. Leukemia inhibitory factor can substitute for nidatory estrogen and is essential to inducing a receptive uterus for implantation but is not essential for subsequent embryogenesis. Endocrinology. 2000;141(12):4365-72. doi: 10.1210/endo.141.12.7855. [PubMed: 11108244].

18. Aghajanova L. Leukemia inhibitory factor and human embryo implantation. Ann N Y Acad Sci. 2004;1034:176-83. doi: 10.1196/annals.1335.020. [PubMed: 15731310].

19. Okita K, Yamanaka S. Intracellular signaling pathways regulating pluripotency of embryonic stem cells. Curr Stem Cell Res Ther. 2006;1(1):103-11. [PubMed: 18220859].

20. Sasaki N, Shinomi M, Hirano K, Ui-Tei K, Nishihara S. LacdiNAc (GalNAcbeta1-4GlcNAc) contributes to self-renewal of mouse embryonic stem cells by regulating leukemia inhibitory factor/STAT3 signaling. Stem Cells. 2011;29(4):641-50. doi: 10.1002/stem.615. [PubMed: 21305673].

21. Imaizumi K, Nishikawa S, Tarui H, Akuta T. High-level expression and efficient one-step chromatographic purification of a soluble human leukemia inhibitory factor (LIF) in Escherichia coli. Protein Expr Purif. 2013;90(1):20-6. doi:10.1016/j.pep.2013.04.006. [PubMed: 23628981]

22. Rose-John S. IL-6 trans-signaling via the soluble IL-6 receptor: importance for the pro-inflammatory activities of IL-6. Int J Biol Sci. 2012;8(9):1237-47. doi: 10.7150/ijbs.4989. [PubMed: 23136552].

23. Fahnert B, Lilie H, Neubauer P. Inclusion bodies: formation and utilisation. Adv Biochem Eng Biotechnol. 2004;89:93-142. [PubMed: 15217157]

24. Kahroba H, Galehdari H, Shafeei M. Expression optimizing and purification of Recombinant human leukemia inhibitory factor (rhLIF) produced in E. coli BL21. Zahedan J Res Med Sci. 2015;17(2):47-51.

25. Darabi P, Galehdari H, Khatami SR, Shahbazian N, Shafeei M, Jalali A, et al. Codon optimization, cloning and expression of the human Leukemia Inhibitory Factor (hLIF) in E. coli. Iran JBiotech. 2013;11(1):4753.

26. Kitamura T, Tange T, Terasawa T, Chiba S, Kuwaki T, Miyagawa K, et al. Establishment and characterization of a unique human cell line that proliferates dependently on GM-CSF, IL-3, or erythropoietin. Cell Physiol. 1989;140(2):323-34. doi: 10.1002/jcp.1041400219. [PubMed: 2663885].

27. Cui S, Selwood L. cDNA cloning, characterization, expression and recombinant protein production of leukemia inhibitory factor (LIF) from the marsupial, the brushtail possum (Trichosurus vulpecula). Gene. 2000;243(1-2):167-78. 